\title{
Miradas antropológicas a las relaciones entre naturaleza y cultura. A modo de introducción ${ }^{1}$
}

\section{Anthropological Perspectives on the Relations between Nature and Culture}

\author{
Pedro Tomé \\ Grupo de Investigación Antropología Comparada de España y América ACEA. \\ Centro de Ciencias Humanas y Sociales. CSIC. Madrid
}

\section{RESUMEN}

A modo de introducción general del volumen, las páginas siguientes pretenden mostrar algunas de las preguntas que, desde sus inicios, la antropología social y cultural se ha planteado cuando ha investigado en las relaciones entre lo que los clásicos denominaban naturaleza y cultura. La exploración de estas relaciones ha sido una constante para los antropólogos de todas las tendencias y orientaciones teóricas por lo que las respuestas a los problemas planteados han abarcado desde la consideración de ambos polos como entes sustantivos de carácter excluyente, hasta la consideración de los mismos como elementos situados en un continuum; desde el biologismo extremo al culturalismo, desde etnoecologías particulares a reflexiones universalizadoras. En cualquier caso, lo relevante de las múltiples perspectivas que se ofrecen es que, en una época en que la globalización ambiental es incuestionable, la antropología inserta su bagaje y su comprensión de la transculturalidad en la búsqueda de soluciones a unos problemas ambientales que se han tornado parte de las discusiones cotidianas de miles de personas en todo el mundo.

Palabras clave: Naturaleza-cultura; Ecología cultural política; Antropología ecológica; Medio ambiente.

\section{SUMMARY}

As a general introduction to the volume, the following pages are intended to show some of the main questions which, from its origins as a discipline, social and cultural

\footnotetext{
${ }^{1}$ Agradezco a Antonio Cea la lectura previa de este texto y sus múltiples sugerencias, así como a Francisco Ferrándiz su continuo apoyo para la confección del volumen.
} 
anthropology has raised when reflecting upon the relationship between what the classics called "nature" and "culture". The exploration of these relationships has been a constant for anthropologists from all theoretical orientations and trends, which means that responses to the problems have ranged from the consideration of both poles as substantive exclusionary entities, to considering them as final points of a continuum; from extrem biologicism to culturalism; from particularist ethnoecologies to universalizing approaches. Anyway, what is relevant to the multiple perspectives that are offered in this volume is that, in an era where environmental globalization is unquestionable, anthropology anchors its understanding of transculturality in finding solutions to environmental problems that have become part of everyday discussions of thousands of people around the world.

Key Words: Nature and culture; Cultural and Political Ecology; Ecological Anthropology; Environment.

La publicación hace ahora ciento cincuenta años de El origen de las especies por medio de la selección natural o la conservación de las razas favorecidas en la lucha por la vida, la obra de Charles Robert Darwin a quien este año se conmemora por doquier, produjo un terremoto en las ciencias sociales. Un terremoto que, al cuestionar las ideas dominantes, afectó tanto a aquellas disciplinas del conocimiento que el decurso de los años había consolidado como a aquellas otras, la antropología entre ellas, que se encontraban en fase naciente. Postular, como hiciera Darwin, que la variabilidad de los seres vivos tiene su razón de ser en la incesante adaptación al entorno equivale a excluir la posibilidad de que lo que existe haya sido creado con el propósito de existir como lo conocemos: si debe adaptarse continuamente, es porque su diseño (design) no es óptimo. Mas insinuar tal idea equivale, como, tras la publicación de El origen del hombre, diría Charles Hodge (1874) en su opúsculo “QQué es el darwinismo?”, a afirmar que el designio (design) mismo, es decir el orden natural armónicamente delineado por la providencia divina, es el que falla.

Más allá de la crítica a los atributos divinos y de las nuevas perspectivas abiertas, si bien esta idea proporcionó pocas respuestas a las inquietudes de los primeros antropólogos, les forzó a hacerse muchas preguntas. Enfrentados a una otredad exótica que la expansión colonial precisaba para autolegitimarse, la incipiente antropología social se vio desafiada por la presencia de numerosos sistemas culturales que, en su diversidad misma, provocaban la fascinación de sus contemporáneos. Pero las inquietudes generadas por la obra de Darwin en un mundo en expansión suscitaban la sempiterna cuestión de si "los otros", los moradores de esas selvas y desiertos que había que comprender y conquistar, tenían alma. O, en terminología más apropiada para la época, si los "primitivos" eran tan humanos 
como "nosotros" o si, por el contrario, estaban revestidos de algún tipo de humanidad diferente -o simplemente no eran humanos- En suma, los científicos sociales del último tercio del siglo XIX se vieron en la necesidad de plantearse la cuestión de qué es lo específicamente humano y, por tanto, qué es lo que nos permite diferenciarnos de lo no humano.

Mas, para alejar esta controversia de una exclusiva discusión sobre principios filosóficos, o aún teológicos, la antropología debía plantear el interrogante de modo que pudiera ser analizado de acuerdo con los procedimientos que estaba estableciendo. Fue así, como desde sus inicios, los antropólogos sociales se vieron abocados a intentar deslindar qué hay en los seres humanos de "natural" y qué de "cultural". O dicho de otro modo, qué hay en lo social de natural y qué en esto de cultural. Así, podrían definirse los modos en que operan las relaciones entre lo humano y lo no humano.

Ahora bien, la aplicación del modelo biologicista darwiniano al ámbito de lo cultural produjo una inmediata aporía. Por una parte, obligaba a defender lo que Geertz (1963: 2) denominó antropogeografía. Es decir, un determinismo ambientalista fundado en el axioma de que los factores ambientales debieran definir las manifestaciones culturales de la misma forma en que habían definido la variabilidad de las especies. Pero, por otra, el mantenimiento de un ortodoxo universalismo evolutivo, que en el ámbito cultural se traducía en la idea de que todas las sociedades habrían de pasar inexcusablemente por las mismas fases de desarrollo socio-cultural, implicaba el desprecio del papel que el medio ambiente jugaba en el avance cultural. De cualquier modo, cuando el particularismo boasiano, en el inicio del siglo Xx, mostró la existencia de profundas diferencias culturales entre comunidades cuyo hábitat era semejante, la antropología se vio impelida a abandonar modelos deterministas y sustituirlos por otros que pudieran dar cuenta de las relaciones entre los seres humanos y el medio en que viven sin abandonarse ni a generalizaciones excesivas, como habían hecho los evolucionistas decimonónicos, ni al propio reduccionismo particularista.

La interrelación entre diversos modelos y orientaciones que se desarrollan y superponen durante el primer tercio del siglo xx (Tomé 2005a) dará paso con Steward a una metodología que investigará regularidades en el cambio social para propiciar leyes culturales de base empírica. Para ello, Steward asumió dos premisas básicas: una noción de evolución multilineal, cuya génesis puede rastrearse en Marx, y la convicción de que a priori es imposible determinar si un entorno es natural o cultural debido a que cada uno de ellos es definido en función del otro. En definitiva, la ecología cultural, afirmará Steward, "presenta un problema y un método. El problema es averiguar si las adaptaciones de las sociedades humanas a sus ambientes 
precisan de modos particulares de comportamiento o si dejan libertad para cierta clase de posibles comportamientos" (Steward 1955: 36). Aún así, la cuestión de si en los procesos de adaptación al entorno es posible verificar paralelismos cuasi universales y establecer niveles generales de desarrollo cultural, como afirma Leslie A. White (1988), o reducidos paralelismos, como postula Steward, solo puede solventarse empíricamente (Tomé 2002).

Sea como fuere, aunque la noción de evolución multilineal permitió avanzar en la teoría antropológica al relacionar la discusión sobre los procesos adaptativos con el análisis de los procesos evolutivos (Sahlins 1960, Service 1971, Harris 1987), casi al mismo tiempo otros antropólogos buscaron la solución a los problemas planteados desde la época de Darwin desarrollando vías de aproximación muy distintas. Tal es el caso, por ejemplo, de la que recorren Roy A. Rappaport (1968) y Andrew P. Vayda (1969) quienes buscarán, sobre todo, explicar los comportamientos de las personas en relación con el medio manteniendo el énfasis en los procesos ecosistémicos y considerando la cultura como un elemento más de los instrumentos específicos que los grupos humanos utilizan para garantizar su supervivencia. O la que, de acuerdo con los principios de la antropología cognitiva (Tyler 1969), busca averiguar los saberes en torno al medio ambiente que poseen otros pueblos o culturas para establecer las bases de etnoecologías particulares.

La conjunción de las distintas corrientes aludidas planteará, a su vez, el problema del diálogo transcultural en la medida en que descubría que la forma en que los diversos pueblos concebían el mundo era heterogénea. Como pondrá de manifiesto la antropología cognitiva, el entorno ambiental y el mundo mismo no son más que constructos socialmente elaborados, por lo que aquello que es tenido por "natural" en ciertos modelos culturales puede aparecer definido de forma muy distinta en otros. En ese sentido, como señala Ph. Descola (1996), la distinción naturaleza-cultura puede relacionarse con una categorización asentada en el pensamiento metafísico occidental que es preciso, cuando menos, relativizar, para comprender cabalmente las relaciones entre los hombres y el resto de los seres vivos en numerosas culturas. Por lo mismo, afirma (Descola 1996: 99) que, frente al dualismo antropomórfico es necesario un monismo antropológico que no conceptualice la sociedad y la cultura como "sustancias autónomas y causales" y haga emerger "un nuevo paisaje antropológico multidimensional en el que azuelas y quarks, plantas cultivadas y mapa del genoma, rituales de caza y producción petrolífera pueden llegar a ser inteligibles como múltiples variaciones de un único conjunto de relaciones que incluyen tanto a seres humanos como a no humanos".

Esta visión del problema, como el intento de Tim Ingold (1993) de superar nociones derivadas de la "globalización ambiental", ponen de mani- 
fiesto, a su vez, que el problema planteado en la época de Darwin —qué es lo natural, qué es lo cultural—, sigue estando vigente en parte porque el concepto de naturaleza, tal y como es utilizado en occidente, hace referencia a categorías de pensamiento diferentes (Ellen 1996). En cualquier caso, a pesar de que este condensado recorrido pudiera sugerir que las aproximaciones que la antropología social ha tenido a las relaciones entre naturaleza y cultura han sido excesivamente dubitativas, lo cierto es que actualmente, en la medida en que la mayor parte de las soluciones a los problemas ambientales exige una actuación transcultural, la antropología se inserta en la "búsqueda de un futuro viable" (Milton 1993: 3) y no se limita a analizar teóricamente tales relaciones. Algo, por lo demás, que es notorio en las páginas siguientes en las que, desde posiciones muy diferentes, se intenta dar respuesta a las cuestiones de qué es lo específicamente humano, qué lo natural, qué relaciones hay entre los dos ámbitos, y cuáles son las mediaciones que se establecen entre ellos.

Así Luis Díaz, muestra cómo, al igual que ocurriera en la época de Darwin con respecto a la discusión del "origen del hombre", la humanización de los animales, y su contrapunto de la animalización del hombre, está propiciando nuevamente discursos reduccionistas, las más de las veces presentados bajo la apariencia de la última novedad científica, que ya han sido desechados por una antropología que asume que lo humano es una condición - no una naturaleza - que, aunque exista una predisposición genética, sólo es alcanzable con la conquista de la cultura. Es decir, el punto de partida de Luis Díaz vendría a postular que lo que confiere a los humanos su identidad es la cultura en cuanto proceso construido y no sólo algunos aspectos, por relevantes que puedan ser, con los que los seres humanos nacemos. Tal sería, por ejemplo, el caso del habla que, dice Díaz Viana, no es más ni menos natural o artificial que la escritura, como lo probaría que sólo somos capaces de hablar tras un largo y duro periodo de aprendizaje. En ese sentido, su reflexión, como la de María García Alonso, sobre los niños ferinos, salvajes o abandonados, muestra cómo se precisa algo que va más allá de lo "natural" para poder adquirir una visión del mundo porque, en última instancia, el lenguaje es una expresión de elementos simbólicos, cabe decir culturales, que, a medida que se incorporan, no solo construyen esa visión sino, además, las herramientas para interpretarlos. En ese sentido, el ser humano es una conquista, dice Luis Díaz, en la que concurren lo natural y lo cultural porque lo natural en el ser humano es ser cultural. No es, por tanto, que en un proceso histórico (o prehistórico) primero viniera el hombre o la mujer y luego el lenguaje —o el alma a la que parece haber sustituido en muchas discusiones-, como tantas veces se lee, porque sin lenguaje no hay humanidad. En ese sentido, afirma Díaz Viana que fue- 
ra de la cultura es imposible lo humano. O dicho en los términos de las iniciales preguntas de estas páginas, lo específicamente humano, lo que nos hace diferentes, es que nos contamos historias. El bomo narrans es singular porque nos permite rememorarnos mediante narraciones que, a su vez, nos construyen. De ahí que diga Luis Díaz que lo específico de la condición humana está en ser un relato en curso que nos contamos los unos a los otros. Y en ese relato se incluyen, por cierto, las múltiples narraciones sobre qué somos, como muestra María García. En concreto, ésta se plantea la cuestión de si pueden ser humanos aquellos que han dado sus primeros pasos en condiciones de ausencia de sociabilidad y, en tal caso, qué condiciones se han de dar para que aquello que no se ha desarrollado siguiendo un proceso "natural", la adquisición de la cultura, llegue a darse en condiciones que faciliten recuperar, si es posible, el tiempo perdido. Si los arqueólogos discuten acerca del homo antecesor, sobre el que en páginas posteriores hablará Julián López, o cualquiera otro es ya humano y Luis Díaz le pide que nos cuente algo para conferirle tal carácter, María García prefiere abandonar la discusión filogenética para centrar su reflexión en la adquisición de humanidad por niños abandonados - o escondidos-. Descubre así que, más allá de los llamativos titulares con que de cuando en vez nos sorprenden los medios de comunicación, existe un género "literario", desplegado a lo largo de varias centurias, que obedece a modelos interpretativos vinculados, a su vez, al contexto en que se desarrollan y propician tales relatos. Característica de este tipo de narraciones ha sido tomar a las criaturas que los protagonizan, siempre indirectamente porque el auténtico protagonista parece ser aquel que las estudia, en instrumentos para la reflexión, cuando no experimentación, acerca de los límites entre la naturaleza y la cultura. En este sentido, la reflexión antropológica encuentra terreno abonado en la analogía que puede establecerse entre la consideración social de estos niños y los grupos indígenas que en diversos momentos históricos han sido "hallados" por los occidentales y vistos, justamente, como niños salvajes.

Ahora bien, la dificultad de concebir a un "salvaje", alguien apegado exclusivamente a lo natural, como un producto social ha precisado de una evolución discursiva compleja. Si tales niños no son humanos, porque son naturales, entonces lo natural no es suficiente para la humanidad. Pero, a la vez, la cultura se presenta como aquello que desvía lo natural de su curso específico y, por lo mismo, como un factor de riesgo para la naturaleza misma. Escapar a las negativas consecuencias que pueden derivarse de este argumento ha sido posible convirtiendo a estos niños en "enfermos culturales", por tanto seres plenamente humanos que precisan de una especial mirada y atención en la que, una vez más, el papel de la ciencia es el de 
salvador de la humanidad manteniendo lo natural y lo cultural interconectado. En ese sentido, los niños que no han llegado a ser humanos todavía, vistos como una representación de "los otros" entre nosotros, son insertados en diferentes modelos culturales en función no sólo de qué se piense que es la naturaleza sino, sobre todo, de la concepción que una sociedad dada tiene de sí misma. Algo patente en la cruda reflexión de Francisco Ferrándiz sobre nosotros mismos.

Si María García plantea la cuestión de cuándo se comienza a ser humano en situación de aislamiento, la páginas de Ferrándiz indagan, so pretexto de algo aparentemente muy alejado, sobre la cuestión de cuándo se deja de ser humano. Acostumbrados como estamos a atribuir la humanidad exclusivamente al momento coincidente con la vida, Ferrándiz se cuestiona si la recuperación de un cuerpo enterrado de manera indigna le confiere dignidad y, por tanto, humanidad. Es decir, de algún modo, la etnografía de Francisco Ferrándiz sobre lo que está aconteciendo en relación con la apertura de las fosas de los desaparecidos en España desde el año 1936, además de ligarse al poliédrico debate sobre la memoria histórica, sugiere que la humanidad alcanza, cuando menos, hasta que otros te recuerdan y que, por tanto, no se deja de ser humano con la muerte.

En el contexto de dicha discusión, se pone de manifiesto cómo el modo mismo en que se muere y, sobre todo, se es enterrado - colocado bajo tierra, quiere decir la expresión- posibilita o niega la condición de humanidad. Aquellos que son "enterrados como perros", es decir, al modo en que en la naturaleza quedan los animales no domésticos al morir, se mantienen en situación de infra humanidad, como personas que han querido ser negadas sepultándolas en tumbas no reconocidas. Es decir, el no reconocimiento de la tumba se traslada a quien está en ella: si no hay tumba no hay humanidad. En este sentido, el "ser tirados", como objetos y no como personas, esa consideración de "perros", de animales, niega la humanidad y se transfiere como concepción dominante al "otro". Es decir, el otro, cualquiera que sea la forma en que se presente, no es humano. Aunque, muchos son los roles que juegan los perros en las sociedades contemporáneas (Tomé 2005), que los asesinados sean vistos "como perros", expresión que utilizan frecuentemente los familiares de los desparecidos, entronca con una larga tradición en la que la asimilación con el cánido es reiterada con frecuencia en España desde la Edad Media cuando "el insulto 'perro' es de ida y vuelta, puede lanzarse contra los musulmanes ('emir... perro de Siria'), o contra los cristianos ('perro bizantino'); aunque también los cristianos pueden utilizarlo contra otros cristianos, como en el Poema de Mío Cid: "perros traidores', de los infantes de Carrión." (Bádenas de la Peña 2004).

En cualquier caso, en un contexto en el que los intereses políticos, ju- 
diciales, sociales e individuales se entrecruzan de tal modo que resulta muy difícil diferenciarlos, salir del bumus, ser exhumado confiere una dignidad que, al reconocer que el fallecido no fue "perro" sino hombre o mujer, rehumaniza. Tenemos, por tanto, cuerpos naturales culturalmente investidos, descompuestos, que fueron de seres humanos que dejaron de serlo por la acción inhumana y que, más allá de la fetichización de los huesos que algunos emparentan con los de las reliquias, pueden volver a serlo a pesar de que fueron muertos hace 70 años si se cuenta su vida y su muerte. En esta disputa, la pregunta ¿cuál es el límite de lo humano más allá de lo cual éste deja de serlo? resulta legítima porque parte de los protagonistas inciden sobremanera en la cuestión de que la humanidad de los enterrados depende básicamente del reconocimiento judicial del crimen, en tanto otros consideran que la mera presencia del cuerpo, como testimonio y memoria, restablece la humanidad al margen de su reconocimiento, o no, por instituciones. Es decir, la utilización de los cuerpos sirve, entre otras muchas cosas, para mediar entre lo social y lo institucional. Por lo mismo, en este marco la reflexión sobre el cuerpo adquiere una nueva dimensión porque deja de ser algo meramente natural para ser algo diferente.

Reflexionar sobre el cuerpo se convierte, por tanto, en uno de los focos en los que puede centrarse el análisis de la relación entre naturaleza y cultura cuando se intenta responder a la pregunta de qué es lo específicamente humano. En ese sentido, los artículos de Julián López y Juan Antonio Flores pueden contribuir a aclarar esta materia en la medida en que plantean concepciones diversas sobre la corporalidad, por muy alejadas que estén entre sí y, a su vez, de la de Ferrándiz.

Sin acudir al lobo del conocido cuento de Caperucita, primer acercamiento al canibalismo de muchos niños y niñas, y pariente de esos "perros" que nos quieren comer (Díaz Viana 2003), pero recordando al no menos popular "sacamantecas", Julián López plantea un diálogo entre diferentes visiones del canibalismo que, de algún modo, entronca con la discusión precedente. Si María García traza un recorrido por diferentes modelos culturales que arrojan luces distintas sobre una misma situación, Julián López plantea que la existencia misma de los caníbales como protagonistas indirectos de numerosos relatos antropológicos, ha permitido el mantenimiento de un mito como realidad contrautópica en el que podían condensarse no pocos de los males sociales. Los empeños de numerosos científicos sociales en mostrar fehacientemente que no existen más caníbales que los de nuestros sueños, han fortalecido justamente la idea de su presencia entre nosotros. Algo de lo que se hacen eco cotidianamente medios de comunicación y revistas científicas que, entremezclando leyendas populares con acontecimientos probados, muestran como rigurosas cavilaciones lo que no son más que con- 
cepciones diversas del cuerpo y de la sociedad supeditadas a luchas ideológicas.

En las mismas, las modernas guías de viajes que sitúan el exotismo al alcance de la mano y de la tarjeta de crédito se convierten, como el cine o ciertas performances artísticas, en instrumento para reflexionar sobre el modo en que los cambios sociales también afectan a la concepción dominante de la corporalidad. Así, más allá del archiconocido Anibal Lecter interpretado por Anthony Hopkins en El silencio de los corderos, Julián López reflexiona sobre algunas de las causas y efectos del amplio "subgénero" del cine caníbal y su vinculación con los modos que utilizan las culturas populares para estrechar las distancias entre procesos naturales y simbólicos. Aunque el caníbal ha condensado históricamente todos los males, a diferencia de lo que ocurre con los niños salvajes, y en cierto sentido del mismo modo, la "perversión" moral se atribuye, en este caso, a lo natural y es la cultura la que al impedir que lo natural siga su curso la que atempera esa abyección. Ahora bien, el positivo desvanecimiento de una percepción de los otros como mal absoluto ha permitido reducir la fetichización del antropófago y su progresiva "normalización" en términos de la cultura occidental que ha generado vías alternativas para dicha inserción. Con ello, el canibalismo se diluye como signo diacrítico de la diferencia y posibilita un diálogo transcultural del que, no obstante, la lucha simbólica no se ha desterrado totalmente.

Justamente por ello, en este proceso, se producen discusiones que, más allá de lo teórico, plantean problemas relacionados con la cotidianeidad de numerosas personas. Por ejemplo, dicha "normalización" permite dejar de considerar la sustitución de una parte del cuerpo propio por otra semejante de otro cuerpo como acto de canibalización. Sin embargo, la legitimación de las transferencias de órganos vitales, al margen de las consideradas legales (recuérdese el artículo de Scheper-Hughes 2005), ha abierto la puerta a otras prácticas, como la ingesta de placentas de recién nacidos, que siguen siendo tenidas por irreverentes aberraciones por una parte de la sociedad en tanto son asumidas por otra que piensa que no existe salto cualitativo entre la misma práctica y la utilización de órganos para la realización de cosméticos. Con ello, aunque de manera diferida, se vuelve a la discusión planteada en el artículo inicial de Luis Díaz, pues, como plantean muchos foros y algunos medios de comunicación, qué hace que una persona con gran parte de su cuerpo trasplantado siga siendo ella misma y no la suma de varias. Responder fácilmente qué es la psiqué provoca de nuevo la crítica del reduccionismo. A su vez, la reducción de este problema por la vía de la sustitución de órganos por prótesis electromecánicas vuelve a plantear la discusión sobre lo específicamente humano: ¿en qué medida, se lee en los mismo foros, se ha deshumanizado o ha ganado en humanidad un 
cuerpo que, sin llegar a Robocop, se mantiene vivo merced a múltiples conexiones "no naturales"?

De cualquier forma si es cierto, como señala Juan Antonio Flores siguiendo a Lévi-Strauss, por cierto uno de los clásicos más citados en este volumen, que la digestión ofrece un modelo orgánico anticipado de la cultura, reflexionar sobre qué comemos —incluyendo nuestros posibles congéneresresulta apropiado en esta pluralidad de miradas a las relaciones entre naturaleza y cultura que proyecta la antropología social.

Y no en vano, el mismo Flores, incardinando sus reflexiones en lo que denomina "antropología de los sentidos" o "antropología sensorial", centra parte de sus páginas en la comensalidad del veracruzano caribe afroandaluz. Desde una etnografía más clásica en su concepción, J.A. Flores Martos plantea un canibalismo diferente, nacido de la proliferación de metáforas en las que la comensalidad carnavalesca no diferencia entre habla y deseo, entre comida y cuerpo. Desde estos parámetros intenta explorar el sentido del gusto desde la sociabilidad, la gastronomía y la sexualidad que comprometen los sentidos en la cotidianeidad veracruzana para descubrir en lo sensorial una retórica identitaria que se despliega a través de categorías variadas. Ahora bien, esa misma retórica compromete al gusto, en sus distintas prácticas, generando lógicas diversas. Así, por un lado, si las retóricas culinarias proceden por saturación de elementos en una barroca lógica fundada en la hipérbole de la enumeración y la yuxtaposición; por otro, las retóricas sexuales hacen alarde de una lógica, que Flores denomina de "ambigú", asentada en la selección y particularización del gusto ante una oferta plural. De cualquier modo, los comportamientos ligados a esa retórica de lógicas múltiples constituyen una parte del entramado de sentidos que dinamizan las vidas de los habitantes del Puerto de Veracruz.

Vida muy diferente a la que tienen los miles de chiapanecos de los que Fábregas habla indirectamente al mostrar cómo los intereses políticos diseñan modelos ecológicos que poseen un gran impacto en la cotidianeidad, al margen de los intereses de quienes tienen que sufrirlos. En este contexto, Andrés Fábregas va a mostrar cómo la utilización de una determinada metodología por parte de la antropología ha podido desvelar las consecuencias de procesos culturales maladaptantes. Fábregas, siguiendo el magisterio de Palerm y Wolf, pone de manifiesto la importancia de las tecnologías hidráulicas como parte de estrategias culturales de adaptación en la conformación de procesos de articulación regional que han servido, a su vez, para la configuración nacional. En ese sentido, centra su reflexión en la pertinencia de la aplicación de las ideas de Steward, profundamente arraigadas en una generación de antropólogos mexicanos, para desvelar los modos en que opera el control político del agua y, consecuentemente de la produc- 
ción de alimentos. Concibiendo la ecología cultural como el manejo cultural concreto de una determinada ecología, plantea la discusión académica habida en México por una etnohistoria que ha permitido la búsqueda de patrones de adaptación de carácter regional. Ésta se ha realizado a través de la conexión del pasado con el presente para comprender la continuidad de una tecnología que probó con creces su eficacia para producir alimentos en grandes cantidades y sostener a ciudades del tamaño de Texcoco o la Gran Tenochtitlán. Desde la misma, sugiere Fábregas, la recuperación del concepto de "sociedad hidráulica" permite concebir las tecnologías relacionadas con el agua como parte de una estrategia de adaptación. En ese sentido, asevera, los conceptos clásicos de la antropología y, particularmente de la ecología cultural política postulada por Palerm y Wolf, siguen siendo válidos para analizar la contemporánea gestión del agua.

El artículo de Fábregas sirve, a su vez, como parteaguas de las reflexiones que plantea el volumen. Si la primera parte se ha focalizado en la discusión de lo específicamente humano, la segunda se centra justamente en lo específicamente natural y sus relaciones con lo humano. Así, al igual que en las páginas precedentes, los artículos de María Cátedra y de Ángeles Valencia tienen, desde puntos de vista diferentes pero complementarios, el agua como eje de la discusión.

María Cátedra, centrando su indagación en el análisis de los comportamientos de las personas que acuden a cuatro balnearios de características diferentes, pone de manifiesto que esta práctica, a camino de lo terapéutico y lo lúdico, adquiere importancia justamente en el momento en que se altera el equilibrio entre el campo y la ciudad. Con el crecimiento de las ciudades, los balnearios se convierten en espacios de trasgresión del orden urbano y acercamiento íntimo con el campo y el paisaje: es decir, en instrumento para mantener y propiciar la ilusión de un regreso a la naturaleza cuando ésta ya ha dejado de ser "natural". Instrumento, por lo demás, vinculado en esos momentos a la "invención" romántica de la enfermedad como excusa burguesa para llevar a cabo ciertas prácticas de ocio y soslayar así las obligaciones cotidianas entre los que ostentan una fuerte ética del trabajo. En cualquier caso, los balnearios se conciben como alternativa a la ciudad industrial, como lugar de descanso que, no obstante, permite mantener las comodidades y costumbres urbanas en paisajes "idílicos". A ello, hay que unir actualmente los cambios en la concepción del ocio que incluye descanso, bienestar físico y psíquico, y el desarrollo de modelos turísticos que buscan el exotismo del pasado y el encanto de una cierta decadencia.

Aún así, sin abandonar la reflexión sobre los valores dominantes de la corporalidad, en la que ya han incidido López y Flores, he insertado en la misma el papel que juega en nuestra sociedad no sólo el cuerpo sino, so- 
bre todo, su apariencia, María Cátedra advierte sobre los riesgos inherentes a cualquier generalización porque los balnearios no se ajustan a un único modelo ni siquiera a una sencilla dicotomía de valores y usos. La dimensión comparativa, de la que María Cátedra ya ha dado prueba en trabajos precedentes, es puesta aquí al servicio del análisis de modelos diferenciados de sociabilidad que tienen que ver tanto con la dualidad sanatorio de la naturaleza-negocio turístico como con las diferencias de clase económica, edad, sexo, etc... de los usuarios. Su reflexión, por cierto, no deja al margen las transformaciones en los usos meramente terapéuticos de los balnearios en los que los tradicionales médicos, expertos en el interior del cuerpo, dejan paso a "asesores de salud" especialistas en el body building externo.

También el agua es el eje del artículo de Ángeles Valencia si bien, en este caso, su reflexión gira en torno a las transformaciones etnoecológicas y de género y el modo en que éstas desvelan cambios identitarios de carácter comarcal que se vislumbran a través de los habidos en el culto a imágenes relacionadas con fuentes y ríos en la provincia de Ávila. De la misma forma que Julián López y Juan Antonio Flores, Ángeles Valencia parte de la convicción de que ciertas retóricas ligadas a etnoecologías particulares han podido generar prácticas sociales que han sido entroncadas con luchas ideológicas. En ese sentido, en la línea de Fábregas, sugiere que el enfrentamiento por el control de las aguas se ha vehiculado históricamente a través de la disputa simbólica por la posesión de ermitas o imágenes. Esto significaría, desde su punto de vista, que ciertas prácticas religiosas han estado, sobre todo, relacionadas con factores ecológicos y económicos u otros referentes de la organización social. Por lo mismo, los procesos de apropiación simbólica y material de lugares en los que el control, distribución y selección de las aguas planteaba problemas sociales sería parte de esa etnoecología cultural producida. A su vez, Ángeles Valencia vendría a sugerir que las transformaciones simbólicas, con "imágenes migrantes" de la Virgen, manifiestan la obsolescencia de unas etnoecologías generadas en sociedades ganaderas.

También Honorio Velasco insiste en la fusión entre naturaleza y cultura que propician las devociones populares centrándose, en este caso, en un santo al que atribuye gran carga polisémica como es San Antón. Al igual que en el artículo precedente, Honorio Velasco constata las transformaciones en las prácticas religiosas como consecuencia del abandono de las explotaciones ganaderas. Sin embargo, considera, a diferencia de lo que plantea Ángeles Valencia, que estas transformaciones concilian nuevamente naturaleza y cultura a través de una renovada ecología que se vincularía a remotos cultos que sirven de mediación entre lo rural y lo urbano.

Para mostrar estas ideas, Honorio Velasco hace un recorrido exhaustivo 
por las variaciones en las prácticas religiosas y sociales vinculadas al culto mencionado intentando, a su vez, ligarlas a modos diferenciados de cultivo y aprovechamiento de la tierra o a ubicaciones en distintos nichos ecológicos. Descubre así que, más allá de la variedad, se han integrado en las formas festivas elementos diferenciales del medio ambiente y de las actividades socioeconómicas hasta constituir tanto marcas en el paso del tiempo como activaciones de ese paso, de ese cambio. Las prácticas festivas relacionadas con este santo viejo o monje joven indicarían, en cualquier caso, una "humanización" de los animales que supone incorporar en el ámbito de lo social y en espacios y territorios característicamente humanos a seres que se consideran irracionales. Por supuesto, estas prácticas no podrían comprenderse, según Honorio Velasco, sin su contrapunto: la "animalización" de los humanos.

Desde presupuestos epistemológicos semejantes a los de Velasco, de hecho recupera la misma noción fenomenológica de "entorno-mundo" que éste usara hace dos décadas (1988), Beatriz Nates abogará por una antropología de las territorialidades para dar una visión antropológica de las formas en que el entorno y el mundo son concebidos por distintos grupos humanos en Colombia, Francia y España. En una línea que diverge de la planteada por J. A. Flores, para Beatriz Nates los conceptos de "mundo" y de "entorno" no son sistemas de reglas inconscientes que permiten a individuos y colectividades ordenar lo sensible. Antes bien, en su opinión, sirven para centrar los contextos en los cuales se producen dichos conceptos y la dinámica que, a través de los mismos, generan los grupos sociales que los definen. Por eso mismo, conviene señalar que, según Nates, ambas nociones no son elementos abstractos con los que el teórico se enfrenta a un espacio físico, sino elementos con los que las personas construyen y materializan territorios en un proceso que exige tanto de la territorialidad - la producción misma del territorio- como de la territorialización - la representación del lugar mismo donde las culturas sitúan discursiva y prácticamente lo que existe-.

Desde estos presupuestos, Beatriz Nates va a establecer una serie de comparaciones para mostrar cómo para algunos grupos humanos que hacen coincidir los límites del mundo con los límites de la humanidad, las clasificaciones de los seres humanos concuerdan con las que hacen del mundo. Más allá de que se detenga en la función territorializadora (o desterritorializadora) que han cumplido santos y vírgenes, al igual que hicieran Ángeles Valencia y Honorio Velasco, o en los procesos de amansamiento, cabe decir humanización, del territorio producido, o en la utilización de la "finca" como medio por excelencia para crear territorio, Beatriz Nates afirma que la concepción de la naturaleza que ciertos grupos huma- 
nos tienen está relacionada con su posibilidad o incapacidad para comprender el entorno como un todo integrado. Por tanto, desde su posición, "pensar el mundo, practicar el entorno" es un proceso correlacional que muestra la territorialización del conocimiento "de las cosas" y el modo en que desde la misma se territorializa el cuerpo de esas cosas. Es decir, hablar de mundo y entorno permitiría categorizar y clasificar personas u objetos, saber cómo y desde dónde actuar con ellas o con respecto a ellas.

También Beatriz Santamarina reflexiona, desde un punto de vista diferente, acerca de los procesos de territorialización y desterritorialización. Ahora bien, al igual que Andrés Fábregas, Santamarina enfatiza los usos políticos de ciertas prácticas culturales para poner de manifiesto cómo en el marco de la globalización se pretende hacer pasar por ecológico lo que, en realidad, es maladaptante. Para ello, desde el diálogo, no siempre afable, con el movimiento ambientalista, Beatriz Santamarina, en la línea de lo que ya planteara en 2006, ofrece un incisivo análisis del tratamiento de las áreas naturales protegidas a través de una regulación de la naturaleza mediante su mercantilización. Es más, su reflexión sobre las áreas naturales pone de manifiesto el conjunto de contradicciones de nuestra praxis cultural en relación con lo ecológico. De entrada, su análisis descubre que un área natural no es natural, sino un espacio políticamente intervenido en función de ciertos intereses que pueden ser presentados bajo la forma de una patrimonialización cultural de la naturaleza en un proceso que, frecuentemente, conlleva otros de apropiación y expulsión semejantes a los de cualquier patrimonialización. En dicho proyecto, las normativas que delimitan los espacios y los usos que se permiten dentro de ellos, terminan igualmente por definir qué es y no es la naturaleza. Y todo ello, partiendo de la premisa no explícita de que la naturaleza es aquél espacio que ha escapado, por el momento, de las leyes de mercado, como si la única explotación y apropiación posible de los recursos fuera la industrial.

Aunque aparentemente los espacios naturales fusionan en su enunciado algo 'dado', lo natural, y algo 'construido', lo cultural, lo cierto es que en su construcción institucional lo cultural aparece como negado para poder subrayar una naturaleza domeñada —un "parque" concebido como espacio cerrado y lúdico- que, en última instancia, al manifestar su dimensión política, deviene mero recurso retórico. Y, con ello volvemos a lo que han planteado, bajo otra formulación, varios de los artículos de este volumen: los parques naturales sirven, entre otras cosas, para posibilitar la naturalización de la cultura y la culturalización de la naturaleza. Como Nuestra Señora de las Fuentes, San Antón, los balnearios, la declaración de derechos de los homínidos o los perros.

Pero, se pregunta Beatriz Santamarina, ¿Qué naturaleza(s) debe ser pa- 
trimonializada(s) para el disfrute de las generaciones futuras? La respuesta política y social, de apariencia tautológica evidencia todas las contradicciones aludidas: se debe conservar la natural naturaleza. Con ello tenemos, nuevamente, la visión de una natural naturaleza naturalizada que convierte en mercancía al alcance de unos pocos el más prístino Edén. Tan salvaje como el de los viajes a tierra de caníbales al que hace referencia Julián López. Tan anclado en el pasado como los balnearios de los que habla María Cátedra. Y, como en su caso, al servicio de la demanda de los visitantes urbanos. Y, aunque el turismo transforma los espacios, apropiándose de los territorios a partir de una reconstrucción física, cultural y discursiva, en última instancia se patrimonializa una naturaleza que puede ligarse a la historia para construir una identidad nacional. Una naturaleza que incluye gente natural. Es decir, en un espacio natural, naturaleza natural, debe haber un pueblo naturalizado que permita un "desarrollo local sostenible".

En definitiva, las páginas de Beatriz Santamarina revelan que es imposible comprender lo 'natural', en cualquiera de sus versiones, al margen de los procesos económicos y políticos. Hace ya casi treinta años antropólogas como Carol MacCormack y Marilyn Strathern (1980), advirtieron sobre la necesidad de concebir la naturaleza y lo natural, la cultura y lo cultural, como constructores culturales y no como entes dados. Cuando se aborda tal intento, se observa la pléyade de intereses, las convergencias políticas, económicas, sociales y culturales que operan en tales campos. En parte, la antropología social puede exhibirlos cuando proyecta dialógicamente múltiples miradas sobre estos problemas sociales. De algún modo, las páginas que conforman este volumen han de servir a tal propósito.

\section{BIBLIOGRAFÍA CITADA}

Bádenas de la Peña, P. 2004. "La épica española y la épica de Diyenís", en H. Ahrweiler. Guerreros europeos de frontera. Tomo III: P. Bádenas y E. Ayensa (eds.). Ressons èpics en les literaturas $i$ el folklore hispànic-El eco de la épica en las literaturas y el folclore hispánico. Barcelona: ACRINET-CSIC.

Descola, Ph. 1996. "Constructing natures. Symbolic ecology and social practice", en Ph. Descola y G. Pálsson (eds). Nature and Society. Anthropological Perspective: 82-102. Londres y Nueva York: Routledge.

Díaz Viana, L. 2003. El regreso de los lobos. La respuesta de las culturas populares a la era de la globalización. Madrid: CSIC.

Ellen, R F. 1996. "The cognitive geometry of nature: a contextual approach", en Ph. Descola y G. Pálsson (eds). Nature and Society. Anthropological Perspective: 103-123. Londres y Nueva York: Routledge.

Geertz, C. 1963. Agricultural Involution: the process of ecological change in Indonesia. Berkeley y Los Angeles, Cal.: University of California Press. 
Harris, M. 1987 [1979]. El materialismo cultural. Madrid: Alianza Universidad. $2^{\underline{a}}$ r. Hodge, Ch. 1874. What is Darwinism? New York: Scribenr, Armstrong and Co.

Ingold, T. 1993. "Globes and spheres. The topology of environmentalism", en K. Milton (Ed.) Environmentalism. The View from Antrhopology: 30-42. Londres y Nueva York: Routledge.

MacCormack, C. y M. Strathern (eds.). 1980. Nature, Culture and Gender. Cambridge: Cambridge University Press.

Milton, K. 1993. "Environmentalism and antrhpology", en K. Milton (ed.) Environmentalism. The View from Antrhopology: 1-17. Londres y Nueva York: Routledge.

Rappaport, RA. 1987 [1968)]. Cerdos para los antepasados. El ritual en la ecología de un pueblo de Nueva Guinea. Madrid: Siglo XXI.

Sahlins, M.D. 1960. Evolution and Culture. Ann Arbor. Mich: University of Michigan Press.

Santamarina, B. 2006. Ecología y poder: el discurso medioambiental como mercancía. Madrid: Los libros de la catarata.

Scheper-Hughes, N. 2005. "El comercio infame: capitalismo milenarista, valores humanos y justicia global en el tráfico de órganos". Revista de Antropología Social 14: 195236.

Service, E. 1971. Primitive Social Organization. Nueva York: Ramdom House. $2^{\text {a }}$ ed.

Steward, J. 1955. Theory of Culture Change. Urbana, III: University of Illinois Press.

Tomé, P. 2002. "Ecología cultural: viejos problemas y nuevas orientaciones", en P. Tomé y A. Fábregas. Regiones y fronteras. Una perspectiva antropológica: 59-72. México: SEPEl Colegio de Jalisco.

Tomé, P. 2005a. "antropología y ecología cultural". Relaciones. Estudios de Historia y Sociedad. 102 (vol. XXVI): 21-59.

Tomé, P. 2005b. "Son como humanos'. Aproximación antropológica a las relaciones naturaleza-cultura a través de los perros en la ciudad", en VV.AA. Los animales. Del rito al mito: 123-154. Salamanca: Centro de cultura Tradicional 'Ángel Carril'.

Tyler, S. A. 1969. Cognitive Anthropology. Nueva York: Holt, Rinehart and Winston.

Vayda, A.P. (ed.) 1969. Environment and Cultural Behavior: Ecological Studies in Cultural Anthropology. Garden City, NY: The American Museum of Natural History.

Velasco, H. 1988. "Signos y sentidos de la identidad de los pueblos castellanos. El concepto de pueblo y la identidad", en L. Díaz Viana (coord.). Aproximación antropológica a Castilla y León: 28-46. Barcelona: Anthropos.

White, L. A. 1988 [1949]. La ciencia de la cultura. Barcelona: Círculo de Lectores.

Fecha de recepción: 15 de enero de 2009

Fecha de aceptación: 20 de febrero de 2009 